\title{
The Development of Foreign Trade and Its Effect on Economic Growth
}

\author{
Chen Lu \\ Tan Kah Kee College, Xiamen University, Zhangzhou, 363105, China \\ luchen@xujc.com
}

Keywords: Foreign trade; Trade structure; Economic growth; Fujian province

\begin{abstract}
This paper firstly reviews the development process of foreign trade in Fujian province, and secondly, by using the data from 1996-2014, the empirical results show that the increase of foreign trade by $1 \%$ will lead to the increase of growth rate by $0.147 \%$. Furthermore, our research indicates that it is the structure of the foreign trade rather than the total amount of foreign trade that makes the most significant contribution to the higher growth rate of economy.
\end{abstract}

\section{Introduction}

Since China open its door for foreign trade, Fujian province as one of the coastal cities in China has experienced great development of international trade since 19802. Basically, the development of trade in Fujian can be divided into four periods.

The first period is from 1980s to 2000. Due to the preferential policy granted by the central government from 1979, Fujian province stated its opening to foreign trade. In 1981, the total value of foreign trade reached 608 million US dollars, with the export value of 401 million US dollars. Four years later, in 1985 the total amount of foreign trade increased to 901 million, more than doubled in the previous 5 years. Right after 1985, the total foreign trade reached more than 1 billion dollars, with both the export and import over 600 million dollars. More specifically, the annual growth rate of foreign trade during 1982-1989 was $25.91 \%$, much higher than the growth rate of GDP during the same period.

The second period is from 2001-2008. With China being a member of World Trade Organization, China as a whole and Fujian as a province braced even more heavily into the international trade. Under the national strategy of the construction of West Coast Economic Zone, a national program stated since 2001, the foreign trade kept increasing from 2001. In 2001, the total value of foreign trade reached 2.26 billion US dollars, and in 2008, this figure increased to 8.48 billion, more than tripled the amount in 2001. Furthermore, the value of total export increased from 1.39 billion in 2001 to 5.69 billion in 2008, and the value of total import also increased from 0.87 billion to 2.78 billion during the same period. It is worthwhile to note that the growth rate of export is higher than that of import. And because of that, the trade surplus of Fujian province increased from 521 million in 2001 to 2.92 billion in 2008.

The third period is from 2008-current. Since the international financial crisis from 2008, the protectionism is prevailing all over the world. Fujian province witnessed a decrease of total foreign trade, the first time to see a minus growth rate of foreign trade in Fujian province. However, after 2010 , the total foreign trade recovered back to 10.87 billion US dollars.

Regarding the development of foreign trade and its effect on the economic growth of China, many researchers tend to analyze from the national wide. Yang and Su (1998) [1] was the pioneering work on this field. By using the 1978-1995 data, their research pointed out that there is significantly positive relationship between them. Following that, many researches $[2,3,4]$ used different empirical method to analyze its relationship. And their results was different from previous research, indicating that the mutual effect was not so clear.

Different from previous researches, this paper focus on the provincial level consideration of foreign trade development and its effect on local economic growth. Rather than conducting empirical research from the national standpoint, we choose Fujian province and conducted detailed tests and 
regression. By applying three index covering different sections of financial sector, our research shows that the development of financial sector is Grange reason to local economic growth, but the economic growth does not necessarily lead to the advance of finance sectors.

The next section gives detailed index construction regarding financial development. And after that, we conduct necessary ADF test, co-integration test and Grange causality test. The last section concludes.

\section{The Effect of Foreign Trade on Economic Growth}

In this subsection, we would like to construct two index for analyzing the effect of foreign trade on the economic growth. More specifically, we will construct two index to measure the degree of development of foreign trade. The first commonly used index to measure the contribution of foreign trade on economic growth is its share on GDP growth. Mathematically, this index can be constructed as

$$
S \equiv \text { Contribution of foreign trade on economic growth }=\frac{\Delta N X}{\Delta G D P}
$$

where $\triangle N X$ measures the change of net export, namely export minus import and $\triangle G D P$ is the change of GDP. Based on the measurement, we could obtain the real data by using the data for Fujian province as the following figure.

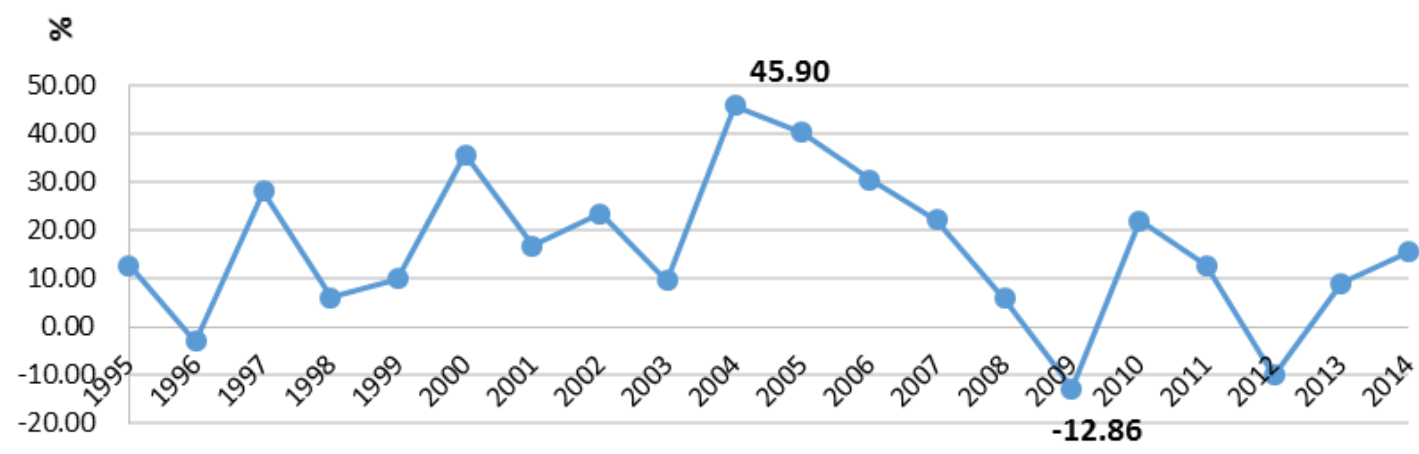

Figure 1. The contribution of foreign trade on economic growth

Another commonly used measurement of the effect of foreign trade on GDP is the pulling effect of foreign trade on the growth of GDP. This index can be constructed as

The pulling effect of foreign trade on the growth of GDP $=S * g_{G D P}$

where $g_{G D P}$ represents the growth rate of GDP and $S$ represents the contribution of foreign trade on economic growth calculated above.

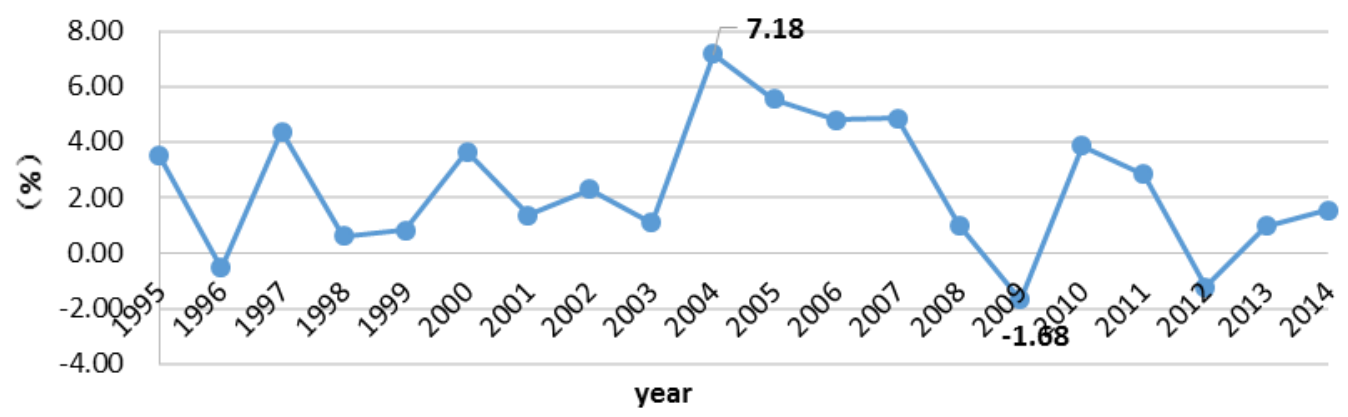

Figure 2. The pulling effect of foreign trade on GDP growth rate 


\section{The Empirical Research on the Structure of Foreign Trade on Growth}

In this sector, we would like to analyze empirically the relationship between the structures of foreign trade on the economic growth of Fujian province. As for the construction of the structure of foreign trade ( $L N M)$, the following index is applied:

$$
L N M=\frac{E M S / E P S}{I M S / I P S}
$$

where EMS and EPS represent the export of manufactured products and of primary products, while on the other hand, IMS and IPS represent the import of manufactured and primary products, respectively. It should be noted that the value of structure of foreign trade is of the logarithmic form.

Stability Test. After we constructed the index to measure the structure of foreign trade, we are in the position to test its relationship with economic growth. Firstly, the stability condition test should be conducted before further investigation could be done. According to the definition of ADF test, the null hypothesis is $\mathrm{H} \_0:[\mathrm{p}]>1$, and the acceptance of the null hypothesis means that the time series data are unstable. The result of the test is summarized as follows:

Table 1 ADF test of LNSP and LNM

\begin{tabular}{cccccccc}
\hline varialbe & $(\mathbf{c}, \mathbf{t}, \mathbf{k})$ & $\begin{array}{c}\mathbf{D}-\mathbf{W} \\
\text { value }\end{array}$ & $\begin{array}{c}\text { ADF } \\
\text { statistics }\end{array}$ & $\mathbf{1 \%}$ critial & $\begin{array}{c}\mathbf{5 \%} \\
\text { critical }\end{array}$ & $\mathbf{1 0 \%}$ critical & Stability \\
\hline LNSP & $(0,0,1)$ & 2.039315 & -0.59649 & -2.74061 & -1.96843 & -1.60439 & Unstable \\
D(LNSP) & $(0,0,0)$ & 2.033749 & -3.77128 & -2.74061 & -1.96843 & -1.60439 & Stable \\
LNM & $(\mathrm{c}, 0,1)$ & 2.058482 & -0.80976 & -4.00443 & -3.0989 & -2.69044 & Unstable \\
D(LNM) & $(\mathrm{c}, 0,1)$ & 2.011491 & -4.21957 & -4.05791 & -3.11991 & -2.7011 & Stable \\
\hline
\end{tabular}

Note: $\mathrm{C}$ is intercept and $\mathrm{T}$ is the constant value and $\mathrm{K}$ represents lag period. The $\mathrm{D}$ represents that first order differentiation is applied.

Co-integration Test. After the ADF stability test, we still need to conduct co-integration test regarding time series data. The detailed regression results can be summarized as:

$$
\begin{aligned}
L N S P= & -2.3195+0.1435 * L N M \\
& (-24.976) \quad(2.167)
\end{aligned}
$$

From this regression result, we can tell that both the constant value and the coefficient value are all significant since their T-statistics indicated by the value in the basket are all over 2 in absolute value. And the result further means that the $1 \%$ change of foreign trade structure could lead to $0.1435 \%$ increase of GDP growth rate.

Grange Test. Because of the nature of the time series data, it is necessary to conduct the causality test before any conclusion could be obtained. And the most common method used for this test is the Granger Causality Test.

Table 2 Grange Causality Test

\begin{tabular}{ccccc}
\hline Null hyphothesis & Sample & $\begin{array}{c}\text { Lag } \\
\text { period }\end{array}$ & F-Statistic & Prob. \\
\hline LNM is not the Grange reason of LNSP & 14 & 2 & 5.90452 & 0.023 \\
LNSP is not the Grange reason of LNM & 14 & 2 & 0.08775 & 0.9168 \\
\hline
\end{tabular}

The result obtained in the Table 3 reveals that there is 0.023 probability to accept the null hypothesis that the LNM is not the Grange cause of LNSP, indicating that LNM is the reason for LNSP. Besides that, there is 0.9168 probability for use to reject the null hypothesis under the $5 \%$ significant level that LNSP is the Grange cause of LNSP, indicating the change of foreign trade structure would cause higher economic growth. 


\section{Summary}

By using the data from 1996-2014 of Fujian province, this paper empirically tackled the relationship between the structure of foreign trade and economic growth. Our empirical research revealed that the development of foreign trade did contribute to the economic growth of Fujian province. More specifically, the increase of foreign trade by $1 \%$ will lead to the increase of growth rate by $0.147 \%$. Furthermore, our research indicates that it is the structure of the foreign trade rather than the total amount of foreign trade that makes the most significant contribution to the higher growth rate of economy.

\section{References}

[1] Yang Quanfa, Su Yuan, 1998. China's export and its effect on economic growth. World Economy and Politics (Chinese), Vol.08, 20-31.

[2] Lai Mingyoing, Xu Helian, 2004. The theory on export and China's economic growth (Chinese), Exploration, Vol. 03, 13-18.

[3] Wang Kun, Zhang Shuyun, 2004. The cointegration analysis of the relationship between China's foreign trade and economic growth (Chinese). Quantitative \& Technical Economics, Vol.04, 26-33.

[4] Chen Haibo, Wei Xiao, 2013. The empirical study on the upgrading of foreign trade and its effect on the change of economic development method (Chinese), Explore on International Trade, Vol.09. 34-40.

[5] Mazumdar J. 1996. Do static gains from trade lead to medium run growth? Journal of Political Economy, Vol.6. 456-481.

[6] Joshua Lewer, Hendrik Van den Berg. 2003. Does trade composition influence economic growth- Time series evidence for 28 OECD and developing countries, Journal of International Trade \& Economic Development, Vol.1

[7] William Maloney, Daniel Lederman. 2012. Trade Structure and Growth. The World Bank Policy Research Working Paper Series, No. 3025.

[8] Levine Ross. 1997. Financial Development and Economic Growth: Views and Agenda. Journal of Econometrics, Vol. 21, 174-189.

[9] Kavoussi,R. M, 1984.Export Expansion and Economic Growth: Further Empirical Evidence. Journal of Development Economics, Vol. 34, 93-110.

[10] [Romer, P., 1986. Increasing return and long-run growth. Journal of Political Economy, Vol.94, 1002-1037.

[11]Romer, P., 1990. Endogenous technological change. Journal of Political Economy, Vol. 98, s71-s102. 